\title{
Work of the European federation of organisations of medical physics (EFOMP) in establishing uniform standards of radiation protection in health care in Europe
}

\author{
P.P. DENDY*
}

(Manuscrit reçu le 19 novembre 1992)

ABSTRACT Over the last two decades, the Commission of the European Communities (CEC) has issued several directives that have an important impact on radiation protection in health care for workers, public and patients. This paper reviews briefly the relevant directives, then considers in greater detail article 5 of the protection of the patient directive (84/166 Euratom) which states that "A qualified expert in radiophysics must be available to sophisticated departments of radiotherapy and nuclear medicine"(1). Work carried out by the European federation of organisations of medical physics (EFOMP) on the interpretation and implementation of this article will then be discussed.

RÉSUMÉ Ces vingt dernières années, la Commission des Communautés européennes a publié plusieurs directives qui ont eu un impact important sur la radioprotection des travailleurs, du public et des patients dans le domaine de l'utilisation médicale des rayonnements ionisants. Ce texte présente, brièvement, les directives se rapportant à ce domaine, puis considère de façon plus détaillée l'article 5 de la directive concernant la protection du patient (84/466 Euratom) qui établit qu'"un expert qualifié en radiophysique doit être disponible pour les installations lourdes de radiothérapie et de médecine nucléaire". Les travaux de la Fédération européenne des organisations de physique médicale sur l'interprétation et la mise en place de cet article sont ensuite discutés.

\section{Introduction}

When directives are issued by the Commission of the European Communities (CEC), member States are required to introduce legislation, within a reasonable timescale, embodying the articles of the directives. The central theme of directives relating to radiation protection has been to achieve uniform basic safety standards throughout the Community. They have stimulated an intensive review of radiation protection practice in health care [9].

* Chairman of the Education, training and professional committee of the European Federation of organisations of medical physics.

** Dept of Medical Physics, Addenbrookes NHS Trust, Hills Road, Cambridge CB2 2QQ, UK. 
A most important group of directives (76/579 Euratom of 1 June 1976, amended as 80/836 Euratom of 15 July 1980, amended as 84/467 Euratom of 3 September 1984) [1-3] lays down the basic safety standards for the health protection of the general public and workers against the dangers of ionising radiation. Its aim is to limit the exposure of the general public and workers by applying the principles of justification, dose limitation and optimisation of protective measures.

The 1980 directive [2] is the most informative and covers all aspects of production, processing, handling, use, holding, storage, transport and disposal of radioactive materials. Subsequent extensions to the directive deal with radiopharmaceuticals and radioactive implantable medical devices. A new directive, currently in draft form, on the design and manifacture of medical devices will apply to all medical devices containing radioactive substances or those emitting ionising radiation without containing any radioactive substance.

There are also two directives relating to the free movement of personnel in the medical profession and in radiation protection. For regulated professions the Commission has already introduced a directive (89/48 EEC of 21 December 1988) [5] detailing a general system for the recognition of higher education diplomas awarded on completion of professional education and training of at least three years duration. The position of staff engaged in radiation protection whose profession is not regulated (e.g. hospital physicists) is not clear.

The other facet of freedom of movement relates to safeguards to ensure that a worker who changes employment or moves from one place of work to another is adequately monitored to ensure compliance with dose limits (90/641 Euratom of 4 December 1990) [6]. This is likely to result in exposed workers being required to carry a radiation "passport" in which an up-to-date record of radiation exposure is maintained. Some hospital staff who move regularly from one hospital to another might be affected by this directive, especially if dose limits are reduced.

Finally, a directive for protection of the patient (84/466 Euratom of 3 September 1984) [3] is specifically related to health care. Article 5 of this directive states that "A qualified expert in radiophysics must be available to sophisticated departments of radiotherapy and nuclear medicine".

\section{The qualified expert in radiophysics (QE(R))}

To facilitate the implementation of this article, CEC officers initiated a study to answer the following questions:

1) Do suitably qualified medical physicists, experts in radiophysics, exist in the member States?

2) Are such experts available in radiotherapy, nuclear medicine and diagnostic radiology? 
3) Is the basic education and training of the medical physicist in European countries a) consistent with the requirements of the proposed directive of the Community on a general system for the recognition of higher education diplomas (89/48/EEC), b) equivalent in all countries, c) recognised by the appropriate government body ?

4) What further education and hospital in-service training is required for the medical physicist to be designated as a qualified expert?

EFOMP and its member organisations were invited to assist with this enquiry.

The first major problem was to define a $Q E(R)$. EFOMP has now proposed the following description :

"The qualified expert should normally be a suitably experienced physical scientist who would be responsible for the safe application of radiological techniques in respect of the protection of the patient. This person would normally work in a hospital, or in a recognised analogous institution and would have knowledge and training in radiation physics appropriate to services where the quality of the diagnostic image or the precision of treatment is important and the doses delivered to patients undergoing these medical examinations or treatments must be strictly controlled".

This description has been accepted by the representatives of the national authorities of member States.

\section{The competencies expected of the QE(R)}

The next problem is to be more precise about what the $Q E(R)$ actually does. Specified in general terms, the responsibilities of radiation physicists in health care will include quality control, radiation safety, replacement of aging equipment, regulatory requirements, educational activities for staff, clinically related needs and administrative functions.

EFOMP has now recognised that it will be easier to achieve harmonization of standards across Europe if the duties of the $Q E(R)$ are expressed in very practical terms. It is therefore working towards a framework where five levels of competency will cover the whole of the career structure of the medical radiation physicist. 
TABLE ।

Descriptions of the five competency levels covering a career in medical physics. Définition des cinq niveaux de compétence recouvrant la carrière de la physique d'hôpital

\section{Competency level}

\section{Training experience}

1 Adequate knowledge in a relevant scientific discipline to a level normally expected of a university degree or equivalent diploma in physics.

2 Adequate span of theoretical knowledge to current state of the art ; able to apply this knowledge with reasonable skill under supervision; able to explain problems to other specialists and discuss response, with appropriate vocabulary.

3 Adequate span of practical knowledge plus a demonstrated capacity for interpreting the state of the art to non-specialist clients, professionals in related disciplines, students, enforcing authorities or administrators ; able to perform given or routine professional tasks without supervision ; able to estimate project budgets, manpower costs and delivery schedules.

4 Demonstrated practical capability for applying theoretical knowledge and experience to give timely, economic and appropriate solutions to particular problems and hypothetical scenarios, fluent communicator, competent presenter of ideas, effective teacher and/or manager.

5 Capability for managing a range of routine services, record of significant contribution to state of the art by initiating/developing research or development, ability to promote new thinking and adoption of novel perspectives ; ability to manage change and resolve conflict.

Descriptions of the five suggested competency levels are shown in Table I. A typical career progression that will result in this experience starts with a good honours degree or equivalent diploma in physics (competency level 1), followed by a period of training (competency level 2), then a period of experience. This will result in a qualified medical physicist (competency level 3 ). Because of the very advisory nature of the work of the $Q E(R)$, often requiring judgement in new or non-standard situations, EFOMP is now considering the view expressed by some member organisations that a further period of experience is required, to competency level 4, before becoming a $Q E(R)$. Competency level 5 would be appropriate for a head of department who was managing a range of routine services.

The duties and responsibilities of the medical radiation physicist in radiotherapy or nuclear medicine can now be assigned competency levels. The examples in Table II are taken from draft proposals for a nuclear medicine physicist. 
TABLE 11.1

Examples of level 2 competence in nuclear medicine Physical characteristics of radiations Exemples du niveau 2 de compétence en médecine nucléaire Caractéristiques physiques des rayonnements

1. Choose appropriate shielding materials to attenuate various types of radiation.

2. Calculate thickness of various materials required to reduce transmitted intensity to any proportion of unattenuated intensity.

3. Design suitable experiments to check calculations.

\section{TABLE 11.2 \\ Examples of level 3 competence in nuclear medicine - Optimisation of exposure \\ Exemples du niveau 3 de compétence en médecine nucléaire - Optimisation de l'exposition}

1. Choice of suitable radionuclide imaging equipment and technique.

2. Choice of radiopharmaceutical and/or radionuclide.

3. Use of thyroid blocking agents.

4. Methods to increase excretion rate.

Extension to level 4 competence is shown in Table III.

TABLE III

Extension to level 4 competence in nuclear medicine

Extension au niveau 4 de compétence en médecine nucléaire

1. Selection of new equipment.

2. Study of less commonly used radionuclides (e.g. for positron emission tomography).

3. Physical and medical aspects of new examinations.

4. Develop dosimetric models for new studies.

5. Application of alternative diagnostic methods.

6. Handling a major spill of radioactivity.

\section{Training for the $Q E(R)$ in the various EFOMP countries}

In 1984, EFOMP issued a policy statement on medical physics education and training [7]. This recommended that postgraduate education in medical physics should include formal courses of lectures, seminars, practicals and tutorial work and a minimum of two years professional onthe-job training. 
More recently (1990), EFOMP has conducted a survey of training programmes, with particular reference to training in radiation physics. Replies have been received from 17 countries, 9 within the European community and 8 outside it. All had introduced a training scheme in accordance with the EFOMP policy statement but 6 were not entirely happy with existing arrangements for the provision of lectures/seminars/ tutorials and 4 felt that current arrangements for on-the-job practical training were unsatisfactory.

Current estimates of the number of physicists completing formalised basic training with the subject areas are shown in Table IV.

TABLE IV

Estimate of medical physicists completing formalised basic training by country Estimation par pays du nombre de physiciens d'hôpital ayant suivi une formation de base formalisée

\begin{tabular}{|c|c|c|c|c|c|c|}
\hline \multirow[t]{2}{*}{ Country } & \multirow[t]{2}{*}{ Total } & \multicolumn{4}{|c|}{ Percentage } & \multirow[b]{2}{*}{ Other } \\
\hline & & Radioth. & $\begin{array}{l}\text { Nucl. } \\
\text { Med. }\end{array}$ & Radiol. & Prot. & \\
\hline Belgium & $0-5$ & 80 & 20 & - & - & - \\
\hline Denmark & $3-4$ & 60 & 20 & 10 & - & - \\
\hline France & 30 & 40 & 20 & 20 & 15 & 5 \\
\hline Germany & $?$ & & & & & \\
\hline Ireland & $3-4$ & - & - & - & - & - \\
\hline Netherlands & 17 & 60 & - & 20 & 20 & - \\
\hline Portugal & $?$ & & & & & \\
\hline Spain & $8-10$ & 50 & 10 & 20 & 20 & - \\
\hline UK & $5-10$ & 25 & 25 & 10 & - & 40 \\
\hline Austria & 4 & - & - & - & - & - \\
\hline Czechoslovakia & $8-10$ & 60 & 20 & 20 & - & - \\
\hline Finland & 4 & 25 & 25 & 25 & - & 25 \\
\hline Norway & $1-2$ & - & - & - & - & - \\
\hline Poland & $10-12$ & 40 & 30 & - & 20 & 10 \\
\hline Sweden & $10-20$ & - & - & - & - & - \\
\hline Switzerland & 1 & - & - & - & - & - \\
\hline Turkey & 8 & 80 & 15 & 5 & - & - \\
\hline
\end{tabular}


EFOMP has also published, a policy statement on the training of a medical physicist as a $Q E(R)$ [8]. In addition to the basic training covered in the previous policy statement, it recommends additional specialist training courses dedicated to the field of application. A period of practical experience is also required working in a clinical environment under the professional supervision of a qualified medical physicist who is already a QE(R).

\section{Advanced training by European Summer schools}

With financial support from the European Community, two such schools for the $Q E(R)$ have now been held. The first, in July 1991 was for the $Q E(R)$ in nuclear medicine and covered all aspects of the work of a nuclear medicine physicist that have protection implications. Both in drawing up the overall programme and in writing my own lectures, I found the competency proposals for nuclear medicine very helpful. The second advanced Summer school, in June 1992, was for the $Q E(R)$ in radiotherapy. Further details on both schools are shown in Table $\mathrm{V}$.

TABLE $V$

Details of the two advanced summer school for the QE(R)

Quelques détails sur les deux cours supérieurs d'été pour expert qualifié en radiophysique

\begin{tabular}{|lcc|}
\hline Date & July $\mathbf{1 9 9 1}$ & June 1992 \\
Subject & Nuclear medicine & Radiotherapy \\
Location & Dublin, Ireland & Seville, Spain \\
No of lecturers & 9 & 15 \\
No of participants & 42 & 45 \\
Countries represented & 17 & 12 \\
\hline
\end{tabular}

* Including associate lecturers.

** Including lecturers.

\section{Future developments and conclusions}

The CEC is currently considering amendment of the directive on protection of the patient and has consulted widely. EFOMP has made strong representations under a number of headings, notably in respect of article 5. For example, the term "sophisticated departments of radiotherapy and nuclear medicine" is particularly unhelpful, especially as the official english and french versions of the article are not exact translations (see abstract). EFOMP has proposed wording which avoids this difficulty whilst clarifying that the "qualified expert" will be a physicist with experience in medical radiation physics. 
In addition, representatives of national medical physics organisations have argued strongly that diagnositc radiology should be included in article 5. This is based on a number of factors - (i) the source of the highest man-made radiation dose to the population is the use of $X$-rays in diagnosis, (ii) a number of complex high dose procedures are now in use, (iii) surveys have shown a wide range of doses for the same examination, (iv) the need for proper training of radiologists. Representatives of national authorities are currently less committed, some on the basis that the case of need has not been adequately demonstrated, some on grounds of cost and some because a significant proportion of the work is already covered by radiation protection services.

In conclusion, the various directives mentioned in the introduction have greatly increased the level of awareness of the importance of all aspects of radiation protection in medicine. All staff groups must make an input to improved radiation protection practice. For physicists EFOMP has already been able to make a significant input on the appropriate way to provide medical radiation physics support for the proper protection of the patient. More work remains to be done but an important route of communication from medical physics staff in hospitals through national organisations of medical physics and EFOMP to the Commission bas been established.

\section{REFERENCES}

[1] EUROPEAN COMMUNITIES COUNCIL. Directive 76/579/EURATOM of 1 June 1976. Lays down the revised basic safety standards for the health protection of the general public and workers against the dangers of ionising radiation. Off. J. Eur. Commun., 12 Jul. 1976, 19, L 187.

[2] EUROPEAN COMMUNITIES COUNCIL. Directive 89/836/EURATOM of 15 July 1980. Amends the directives laying down the basic safety standards for the health protection of the general public and workers against the dangers of ionising radiation. Off. J. Eur. Commun., 17 Sept. 1980, 23, L 246.

[3] EUROPEAN COMMUNITIES COUNCIL. Directive 84/466/EURATOM of 3 September 1984 . Lays down basic measures for the radiation protection of persons undergoing medical examination or treatment. Off. $J$. Eur. Commun., 5 Oct. 1984, 27, L 265/1.

[4] EUROPEAN COMMUNITIES COUNCIL. Directive 84/467/EURATOM of 3 September 1984. Amends directive 80/836/Euratom as regards the basic safety standards for the health protection of the general public and workers against the dangers of ionising radiation. Off. J. Eur. Commun., 5 Oct. 1984, 27, L 265/4.

[5] EUROPEAN COMMUNITIES COUNCIL. Directive 89/48/EEC of 21 December 1988. A general system for the recognition of higher education diplomas awarded on completion of professional education and training of at least 3 years duration. Off. J. Eur. Commun., 24 Jan. 1989, 31, L 19.

[6] EUROPEAN COMMUNITIES COUNCIL. Directive 90/641/EEC of 4 December 1990. On the operational protection of outside workers exposed to ionising radiation during their activities in installations at which such radiation is used. Off. J. Eur. Commun., 13 Dec. 1990, 32, L 349. 
[7] EUROPEAN FEDERATION OF ORGANISATIONS OF MEDICAL PHYSICS (EFOMP). EFOMP Policy statement 1984. Medical physics education and training : the present European level and recommendations for its future development. York : EFOMP office, c/o Institute of physical sciences in medicine.

[8] EUROPEAN FEDERATION OF ORGANISATIONS OF MEDICAL PHYSICS (EFOMP). EFOMP Policy statement 1988. Radiation protection of the patient in Europe : the training of the medical physicist as a qualified expert in radiophysics. York: EFOMP office, c/o Institute of physical sciences in medicine.

[9] FITZGERALD M., COURADES J.M., Eds. Medical radiation protection practice within the EEC. London : British institute of radiology, 1991. 